\title{
One year pituitary function follow-up in survivors of severe brain injury presenting at a regional neurosurgical centre.
}

I Onac ${ }^{1}$ and Zaka Haq ${ }^{1}$, S Elyas ${ }^{1}, \mathrm{~S}_{\text {Leeder}}^{2}$

Princess Royal Hospital \& Hurstwood Park Neuroscience Unit, Haywards Heath, West Sussex, UK

\section{Introduction}

$5 \%$ of traumatic brain injuries are severe (NICE)

30\% develop hypopituitarism 3 to 12 months later i.e.

- Human growth hormone deficiency (the most common )

- Hypocortisolism / Hypothyroidism /Hypogonadism

- Diabetes Insipidus

Currently there are no UK guidelines to advise on the follow up of such patients

\section{Patients}

Individuals with severe head injury admitted to Hurstwood Park Neurosurgical Centre between 1st January 2010-31st December 2012 Severe head injury defined as GCS of 8 and below

\section{Methods}

\section{Retrospective analysis of}

- Head injury nurse data base

- Hospital electronic data base

-Department of Pathology database (Including pituitary function tests )

-Primary care computerised records

\section{Results}

Patient demographics:

\begin{tabular}{|ccc|}
\hline Female & Male & Total \\
\hline 4 & 32 & 36 \\
\hline
\end{tabular}

\begin{tabular}{|lcc|}
\hline & Interval & Mean \\
\hline Age & $16-72$ & 36 \\
\hline $\begin{array}{l}\text { Length of } \\
\text { Hospital } \\
\begin{array}{l}\text { Admission } \\
\text { (days) }\end{array}\end{array}$ & $12-266$ & 70.5 \\
\hline
\end{tabular}

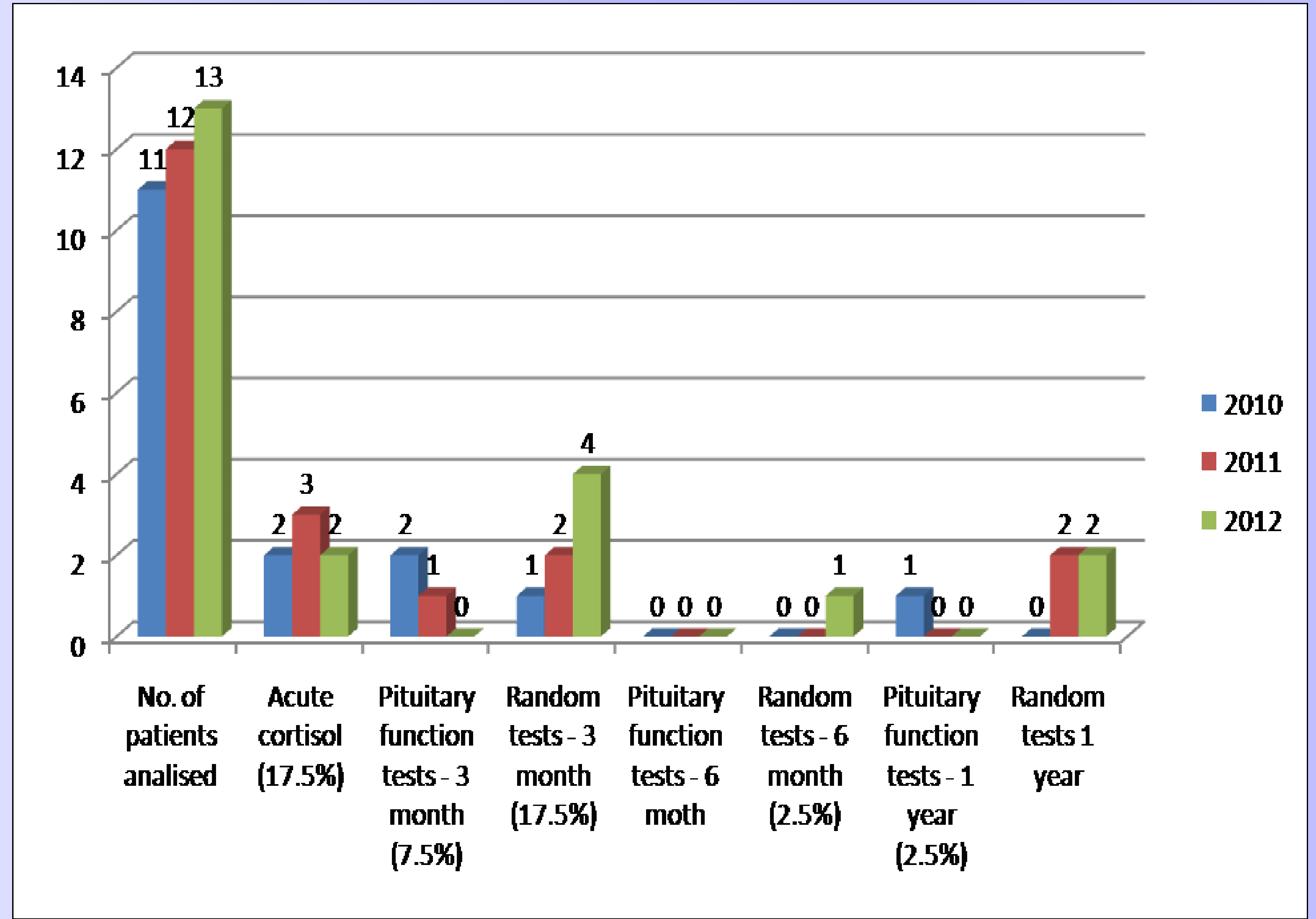

\section{Conclusions}

1. More than $2 / 3$ of patients had no pituitary function tests.

2. Thus up to $30 \%$ could have had unrecognized pituitary dysfunction

3. There is a need for guidelines to inform the endocrine management of these individuals following discharge from the neurosurgical centre

\section{Changes Implemented}

- A Pituitary function test 'checklist' has been developed

- Endocrine tests will be done 3/6/12 months post injury

- This strategy will be coordinated by the Head Injury Specialists Nurses

in collaboration with the rehabilitation units \& Primary care

- A repeat audit will be carried out in twelve months. 
